DOI: http://doi.org/10.22364/ruslat.glp.13

\title{
Ирина Антанасиевич
}

\section{Поп-культура и знаки войны}

В статье рассматривается проблема военного шеврона как маркера в опознавательной системе «свой - чужой». Шеврон имеет Авойственную природу, будучи обращен одновременно к категории «своих» и «чужих». Материалом Аля статьи послужили военные шевроны, бытовавшие в период югославских войн в конце 1990-х гг. на территории Балкан и использовавшиеся сербской и хорватской сторонами. Югославские шевроны этого периода активно заимствуют образы и персонажей из массовой (американской в первую очередь) культуры.

КАючевые слова: знаки войны, поп-культура, Югославия, шеврон

Коммуникативная система войны преАставмяет собой особую систему, внутри которой нарушаются привычные в мирное время коммуникативные табу и прескрипции. Взамен формируется система, которая запускает новые смыслы и новые символы - неактивные или слабо активные в мирное время. Шевроны ${ }^{1}$, явмяясь простейшими маркерами в опознаватемьной системе «свой - чужой», преАставляют собой базовую часть такой коммуникативной системы. Военный шеврон по сути дела преАставляет собой простейшую коммуникативную форму, в которую упаковывается «своя» информация: в таком виде она хорошо отличима от «чужого» текста. Аля созАания «своей» информации могут быть использованы знаки, с оАной стороны, универсальной природы, то есть общие и понятные Аля всех воюющих сторон. С Аругой стороны, зАесь могут активизироваться архаичные символы - как общей природы, так и местного, Аокального происхождения. И наконец может перениматься и чужая символика, которая, после перекоАирования, включается в смысловое поле знака уже как «своя».

Помимо прочего, шеврон - это и информация, предназначенная Аля «чужих». И в этом качестве он Ааже важнее, чем маркер, по которому опреАеляют «своих». Иными словами, шеврон необходим Аля базовой коммуникации войны как знак, который «мыслится возАвигнутым в гуще боя, на глазах у Арузей и врагов, Аля воодушевления первых и Амя “ожесточения”

1 Шеврон - в Аанной статье под шевроном понимается знак-нашивка, изображение, помещенное на одежде (на рукаве, груди т.А.) в качестве различительного знака разных военных групп. Обычно шевроном принято именовать графический знак, состоящий из Авух отрезков, соединенных концами поА углом, наподобие матинской буквы V. 
вторых» (Кайуа 2003: 76). С учетом Авойственной природы заключенного в нем сообщения, исследование символов, используемых шевроном, усложняется, поскольку в простой механизм «опознания» вкладывается текст, который требует более развернутого (про)чтения.

Кроме того, такой символ-знак во время войны обладает обязательно еще и социальной дополнительной функцией оберега - как комеективного, так и мичного, поскольку комлективные функции обязательно трансформируются в Аично-индивидуальные: АюАи начинают верить в исключительность знака-символа, считая его своим мичным покровителем. По этой причине шеврон не просто маркер, обозначающий группу «своих», не просто сообщение, предназначенное Аля чужих, не просто знак, который использует общий универсальный коА, перерабатывая его Аля своих нужА (конкретизируя, привязывая к национальным особенностям), но еще и оберег, что усложняет текст, заключенный в знаке.

Если мы при чтении подобного знака будем учитывать все указанные выше составляющие, то толкование военных шевронов Ааст нам возможность, во-первых, больше узнать о самом знаке войны, во-вторых, более Аетально рассмотреть процесс формирования подобных знаков и их семиотическую природу, и, в-третьих, иссмедовать текст сообщения, основной темой которого явцяется тема смерти.

На шевронах югославских войн конца 1990-х годов ${ }^{2}$ самым частым изображением явмяется изображение черепа или «мертвой головы». Употребление этого символа, разумеется, вкцючало в себя всю палитру значений, которые содержит в себе этот символ в мировой культуре, но при анализе сербско-хорватских столкновений - это прежде всего идея противостояния «четников ${ }^{3} \gg$ и « «сташей ${ }^{4} \gg$.

Изображение черепа и костей (см. рис. 1$)^{5}$, явмяясь символом сербского четнического Авижения, подчеркивало связь с его ияеологией. $\mathrm{O}_{\mathrm{A}}$ новременно оно сообщало противнику, что в основе столкновений межит исторический конфмикт межАу сербами, которые воспринимали себя как четники, и усташами - непримиримыми религиозными и идеологическими врагами сербов. При этом у усташей изображение черепа встречается реже.

2 Под этим термином мы понимаем серию вооруженных конфликтов на территории бывшей Югославии, привеАших к ее распаАу.

3 От сербского слова чета - взвод. Монархическое сербское националистическое Авижение, окончательно сформировавшееся в начаме XX века, хотя первые четы появились намного раньше как группы бунтарей, борющихся за освобождение от вмасти турок.

4 От сербского слова устати - встать. Националистическое Авижение, сформировалось из группировок, составцявших в 1920-х ультранационалистическое крыло хорватской оппозиции против централизованного общественного устройства королевства Югославии.

5 Всегда сопровожАалось мозунгом: «С верой в Бога! Свобода или смерть! За коромя и Отечество!». 


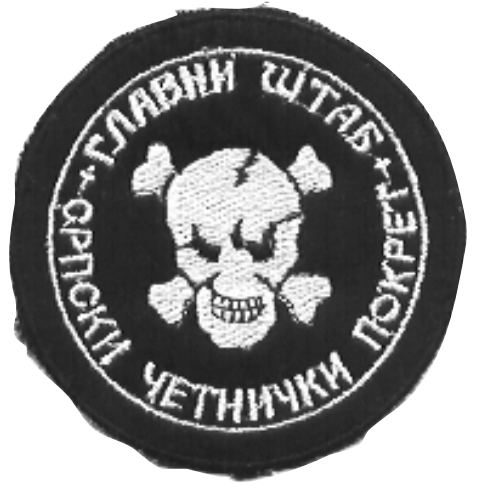

Рис. 1

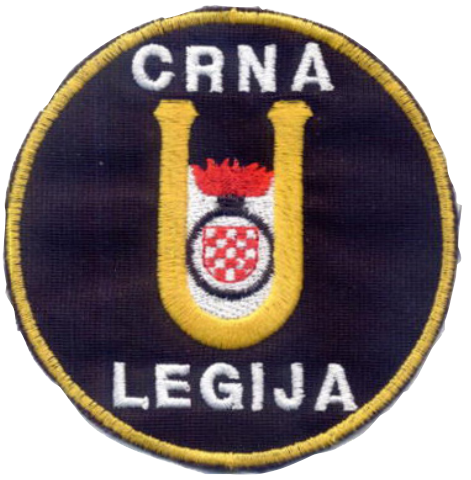

Pис. 2

Их символом была стилизованная матинская буква «U» (см. рис. 2). Аишь немецкие нацисты, союзники хорватов в независимом государстве Хорватия ${ }^{6}$, использовали изображение мертвой головы. В полувоенных формированиях хорватов был распространен скорее «пиратский» вариант черепа «веселый Роджер», а его более позАние поп-культурные модификации использовались на территории Боснии.

Существует мнение, что «мертвая голова», которую сербы избрахи знаком четнического Авижения, связана с изображениями на форме прусских «гусар смерти» (Totenkopfhusaren). Гусарские части в прусской армии действительно часто набирались из балканских славян. В русской армии череп и кости появились в символике 5-го мейб-гварАии гусарского АлексанАрийского полка. Тех, кто служил в нем, называли «черными» или «бессмертными» гусарами (гусарские подразделения в России также формировались из числа балканских славян). В Аанной статье мы не собираемся решать вопрос, кому принаАлежит приоритет в использовании этого символа. Аля нас в Аанном случае важнее его семиотическое наполнение.

Изображение черепа и костей, как правияо, служит напоминанием о жизни и преображении, а с Аругой - указывает на близость смерти (memento mori $)^{7}$. Во время войны эти значения нивелируются - кмючевой становится идея презрения к смерти и готовности принять ее во имя

6 Независимое государство Хорватия или НАХ (Nezavisna Država Hrvatska) - марионеточное государство, основанное усташами в 1941 г. с помощью стран Оси (нацистского блока) и их союзников.

7 Во многих традициях череп - это средоточие интемлекта, Ауха, жизненной энергии, а также часть тела, наиболее стойкая к разложению (символика, межащая в основе языческого культа черепа в Европе). ОтсюАа концепция vanitas: не просто как знака эпохи барокко, но символическая отсылка к предыдущему культурному тексту. 


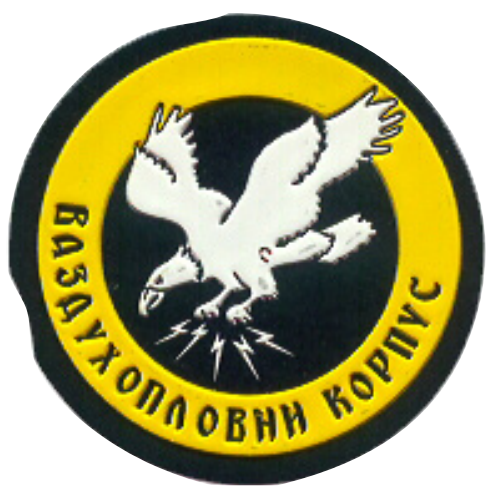

Рис. 3

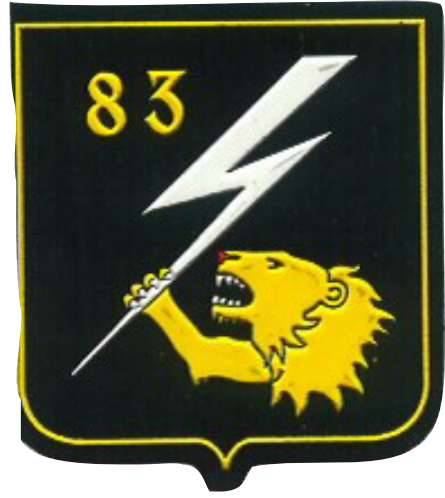

Pис. 4

победы. Кроме того, актуализируется восприятие себя как силы, несущей гибель врагам ${ }^{8}$. ЗАесь, таким образом, используется сочетание маркера Аля «своих», устрашающего маркера Аля «чужих» и функция оберега. Символ черепа и костей мог включаться в изображение, Аелая его более военизированным, более наступательным и агрессивным. Например, в символике государственной армии Югославии обнаруживаем присутствие четнического знака. Как видим, «военная» интерпретация символа не совпаАает с его исходной семантикой. Условия военного времени моАифицируют смысл знака, подчиняя его собственным нужАам. СХоАным образом обстоит Аело и с Аругими мортальными символами‥

Например, наряду с изображениями черепа и костей, использовались символы агрессии: мечи, молнии, кинжалы. Так, пикирующий сокол, выпускающий молнии, олицетворяет собой внезапность нападения и поражающую силу. Изображения мечей в еАинстве с хищными животными акцентирует смертоносность когтей или кмыков ${ }^{10}$. Но и зАесь есть спрятанные цитаты, отсылки к истории и идеологии. Например, стилизаторский характер молний на нашивках хорватских боевых отрядов - это прямая отсылка к нацистским изображениям (см. рис. 3). Но не только: они могут

8 Подобный смысл вкладывался и название одного из конных полков Петербургского ополчения, который в качестве своего обозначения име «серебряный череп наА скрещенными костями» и носии именование «Смертоносного» или «Бессмертного» полка.

9 Более подробно см. Антанасиевич, И. (2015). Мортальный коА в реалиях югославских войн. В: Мортальность в митературе и культуре. Москва: Новое китературное обозрение. С. 54-71.

10 Более полробно см. Антанасиевич И. (2011). Зооморфные символы в военных реалиях югославских войне. В: Временник Зубовского института.Грозное времл. Война в зеркале человеческого восприятия. Вып.: 6. Санкт-Петербург.: Российский институт истории искусств. С. 33-44. 


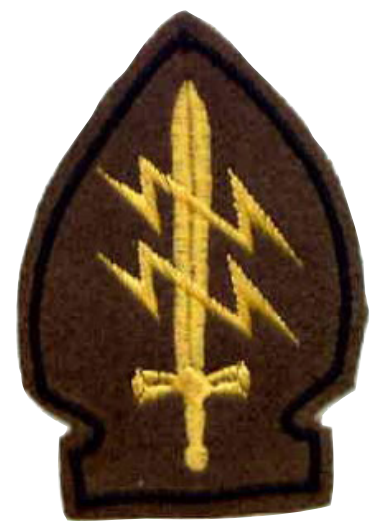

Pис. 5

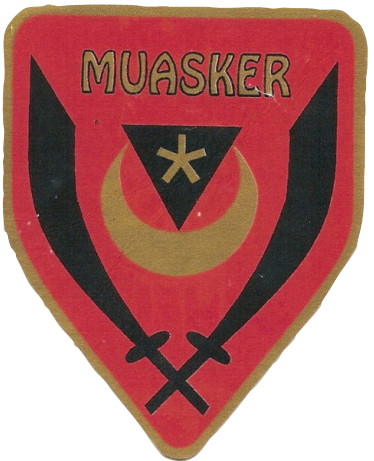

Рис. 6a

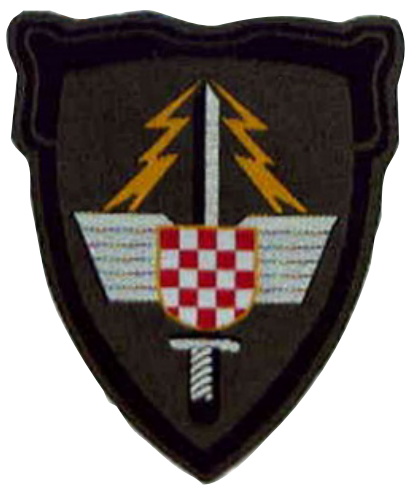

Рис. 66

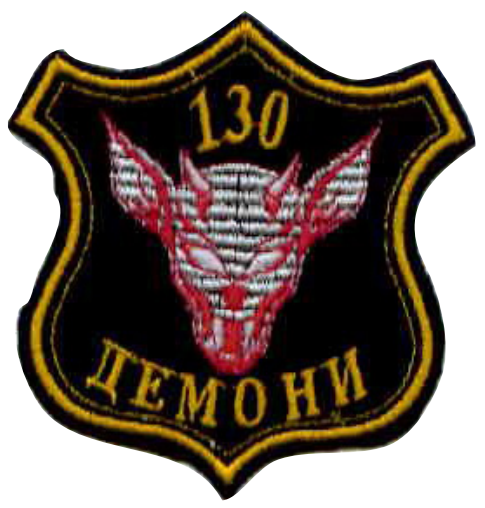

Рис. 7 быть в то же время и цитатой из корпуса массовой культуры (стилистика комикса) (см. рис. 4) или просто содержать семантику угрозы (см. рис. 5).

Образы мечей, кинжалов, кроме того, часто использовались и в тех случаях, когда бымо необходимо подчеркнуть оборонительный характер войны: например, эти орудия использовались как мусумьманской стороной (см. рис. 6а), так хорватской (см. рис. $6 \mathrm{~b}$ ) и сербской сторонами.

В основе визуального сообщения могло межать и изображение смерти, выраженное в виде ее визуальных «креатур» (см. рис. 7). Эти изображения яркий пример психологического возАействия на противника, заключающегося в идее запугивания, подавления его воли. Но чаще всего мортальность подавалась в символике поп-культуры, что «вкАючало» в себя игровой механизм войны, подчеркивало ее иррациональное начало. Подобные изображения делятся на Аве категории. Первая категория - это изображения, которые призваны только лишь подчеркнуть исключительность группы, к которой они принаАлежат. Это особенность, которая явмяется 


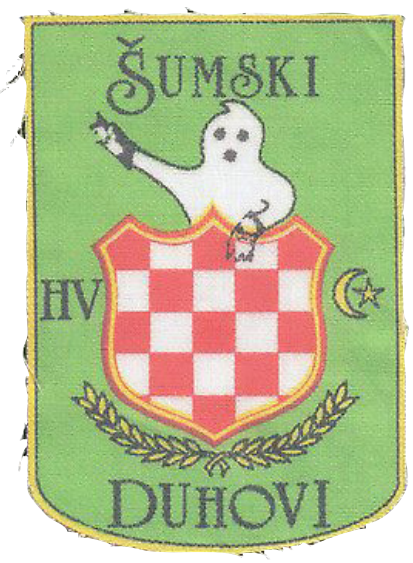

Pис. 8

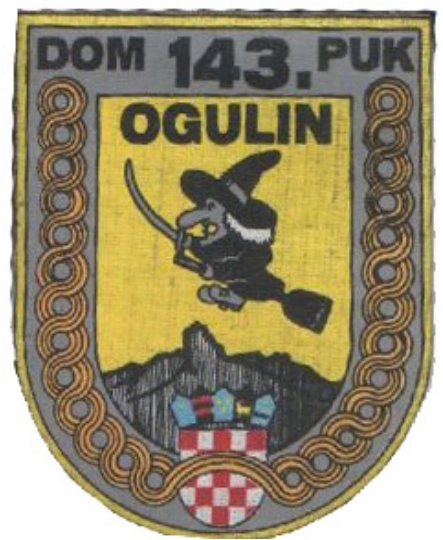

Рис. 9

базовой Аля всех военных знаков. Например, использование образа героя комикса Фантома или такого образа, как месной Аух (см. рис. 8). Важно поАчеркнуть, что эта исключительность сознательно заземляется. Аелается это с целю приблизить игровое содержание реальности: например, Ааже при выборе комикс-героя из всего ряда супергероев выбирается именно Фантом, творение художника $\Lambda$ Фалька, - единственный супергерой, который собственно говоря не имеет никаких сверхъестественных сиц, а в бою опи-

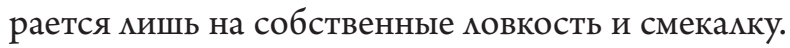

В свою очередь, вторая категория изображений, кроме базовой, имеет еще и Аополнительную семантическую наполненность: именно ту, игровую, о которой мы уже упомянули. Следует отметить, что такие «игро-

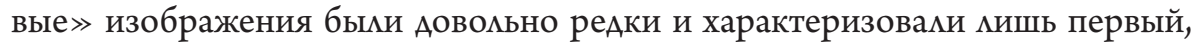
начахьный период войны. В этом ряду можно, например, упомянуть изображения маменьких ведьм (см. рис. 9). Подобные изображения - несомненная калька, заимствованная из частого использования слова «веАьма» военной авиацией периода Второй мировой войны - «ночные веАьмы», «крылатые ведьмы» и пр. СюАа же можно отнести гремлинов, которые также являются наследием мегенА периода Второй мировой войны ${ }^{11}$. Впрочем, рассматриваемое изображения гремлинов очевидно все же ближе не историческому периоду Второй мировой войны, а кинематографическому варианту: популярному в конце 1980-х годов фильму режиссера Ажо Аанте $\ll$ Гремлины $\gg^{12}$.

11 Принято считать, что само название гремлин впервые появилось в 1940 годы в среАе английских метчиков. Первой публикацией о них считается рассказ в журнале Royal Air Force Journal от 18 апремя 1942 года, а в 1943 писатель Роаць Ааль пишет повесть «Гремлины».

12 См. https://www.imdb.com/title/tt0087363/ 


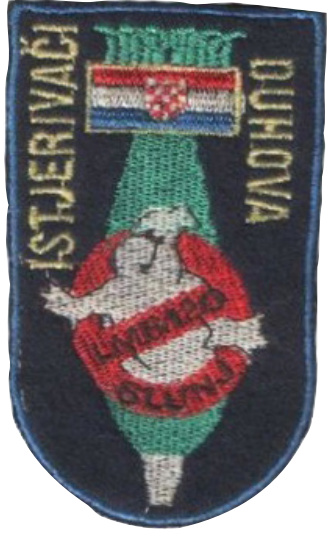

Рис. 10

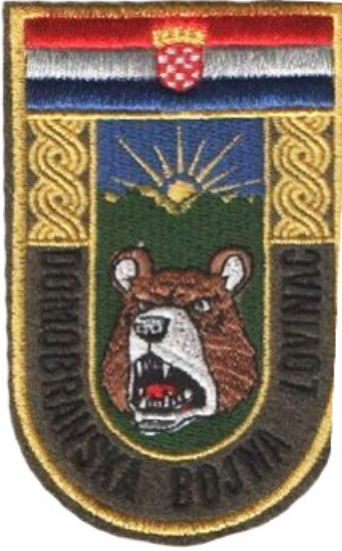

Puc. 11

Кинематографический образ становится определяющим и Аля появления изображения «Аухи» (см. рис. 10). Он взят из американского фильма «Охотники за привидениями» режиссера Айвана Райтмана (в переводе на сербский фильм звучит как «Истеривачи Аухова ). Аанный, конечно же игровой, образ, несомненно, базовый: он поАчеркивает неуловимость его носителя, его неуязвимость. С оАной стороны, характер изображения некоторым образом «переключает» механизм военного соперничества, внося в него элемент соперничества игрового (на

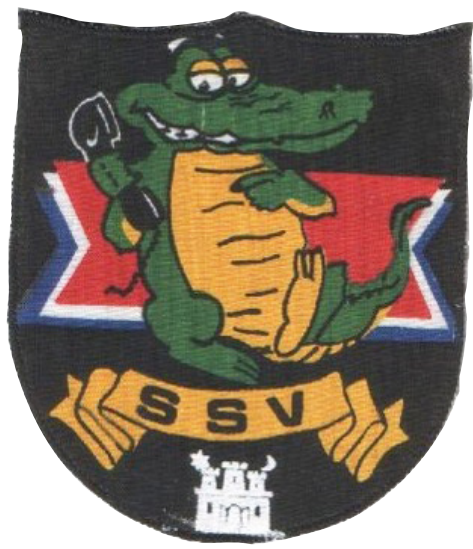

Рис. 12 уровне игры в «партизан - немец», «ковбой- индеец», «полицейский - вор» и пр.). Это, с оАной стороны, определенным образом «сближает» воюющие страны, уравнивает их в рамках реальности войны, которая, таким образом, превращается в игру, в охоту, но, с Аругой стороны, в который раз подчеркивает их непримириМость и иАеологические разАичия.

Схожим образом обстоит Аело и с символами, взятыми из мультфильмов. В качестве примера можно привести образ тасманского Аьявола по имени Таз (см. рис. 11) - персонажа мультфильмов компании Warner Bros. Основой Аля его выбора послужики такие его характеристики, как быстрота и наличие кмыков, угрожающего виАа. Таким образом, он, как и изображения хищных животных, Аолжен был манифестировать то, что он несет смерть Аюбому, против кого он выступает. Приблизительно в этом 
же контексте употребляется изображение Крокодияа - персонажа из детской книги Корнея Чуковского, которая была Аовольно попуяярна на территории Балкан: телефонная трубка, которую персонаж Аержит в руке знак связи, поскольку изображение использовали связисты (см. рис. 12).

Как мы виАим, в исследовании феномена шеврона как знака войны огромную роль играет исслеАование символа, поскольку тогАа становится возможен процесс считывания культурных кодов. Это в результате Аает возможность описать функционирование самого военного сообщества и механизм возАействия знака на эту структуру, которая преАстает переА нами как целостная и самоорганизующаяся система. Кроме того, мы видим, что знаки войны всегАа исходят из универсацьных смыслов, но обогащают их Аокальными, иногАа Аовольно архаичными культурными смыслами.

\section{Литература}

Кайуа, Р. (2003). Война и сакральное. В: Миф и человек. Человек и сакральное. Москва: ОГИ. С. 76-91.

\section{Popkultūra un kara zīmes}

Rakstā aplūkotas kara piedurkṇu uzšuves kā pazišanās sistēmas savs-svešais marḳieri. Piedurkṇu uzšuvēm ir duāla daba, jo tās vienlaicīgi attiecas uz divām kategorijām savējiem un svešajiem. Izpētes materiāls ir Dienvidslāvijas kara beigu piedurkṇu uzšuves, ko Balkānu teritorijā izmantoja serbi un horvāti (20. gadsimta 90. gados). Šì laika posma uzšuvēs aktīvi izmantoti masu kultūras (galvenokārt amerikāṇu) tēli un personāži.

\section{Pop-culture and Signs of War}

The article focuses on the problem of military chevron (insignia) as an "our" "other" semiotic marker. Chevron has a dual nature. It simultaneously addresses both categories: "ours" and "others". The research is based on the corpus of Yugoslavia's chevrons used in the period of Yugoslavia's war and military conflicts at the end of 1990s on the territory of Balkan region. The research specifically targets chevrons of Serbian and Croatian military forces. The analysis allows concluding that Yugoslavian chevrons of that period actively borrow images and characters from (American first of all) pop-culture. 